\title{
Leadership Role in Making Effective use of Innovation in Industry 4.0
}

\author{
S. Sridhar
}

\begin{abstract}
Success for industry 4.0 implementation in today's markets and those of the future depends heavily upon role of leadership. There is enough research in the past on leadership style behaviour and change management, researchers have also concluded that no single style is effective, yes Situational and participation is better than the autocratic style, while we debate what style would be appropriate leadership style behaviour and change management all are crucial, these needs to be explored and tailor made to suit industry 4.0.

Literature review is done to understand and share the recommendation on Leadership style, behaviour and other factors which the leader should drive / promote for effective implementation of Industry 4.0.
\end{abstract}

Keywords: Leadership Style, Leadership Behaviour, Knowledge Management, Change Management.

\section{INTRODUCTION}

This Research on leadership styles and the need of right behaviour is done extensively in past few decades, All the theories have concluded the merits and demerits of one style over the other and the necessary behaviours required, however clear definite outcomes has not been arrived nor is possible and should not be expected too.

What can be concluded or referred that one style can be made prominent which will lead to the business successes. This paper tries to bring the light.

Industry4.0 will bring lots of changes both on the leadership qualities and the behaviour demonstrated by leaders and followers, everyone agrees that Industry 4.0 not only drives new technologies and new products and services. "This also creates conditions for mastering the ever-increasing dynamics and complexity of existing and new markets. Companies that can play a role in multiple areas seem to have a particularly good starting position. it is important to recognize the added value as it also implies high effort that must be amortized by increased productivity with a corresponding reduction in costs", Thomas brand(2013)

Industry 4.0 implementation is not clear, few companies which have advanced have problems in use of excessive technology, or lack of capability to make effective use or it creates a new Phycological stress which increases the iteration rate.

The Phycological stress due to boredom is to be watched

Revised Manuscript Received on December 05, 2019.

* Correspondence Author

S. Sridhar*, School of Management, SRM Institute of Science and Technology, Chennai. E-mail: shreedhar119@gmail.com out, coupled with there are other challenges, the challenge of resistance to change, challenges due to lack of new skills, challenges due to teething problems and challenges of boredom (silo Syndrome). There is also a myth that the need of human mind is less required or limited and communication in the form of instructions and solutions will be digital and predefined. All these give new threat towards ownership and creativity ...

"In the interests of making Industry 4.0 a success we cannot shy of our responsibilities by not addressing few critical engagements. The focus should be involvement and engagement of employees in terms of up skilling their skills and create a process which will have motivated workforce and bring a engaged work environment. Training and up skilling to be encouraged for lifelong development." Henning (2013).

"We will also see new human and technology interface through Industry4.0. It will be machines that work to the needs of human beings"(Nat, Wolfgang,2013)

As a leader he/she must make a team (varied knowledge levels compared to teams in Industry 1.0 and 2.0), There for understanding relationship between team work and team members performance indices is an important factor for the leader. "The impact of team performance depends between team work and the KPIs reviewed leader helps to build the team and its member an improved confidence level's, team satisfaction, effectiveness and builds a strong bonding within the members which help in the work (Toni, Maria and Eileen 2003). "This finding is with the many authors suggest that the industry 4.0 will bring pressure in the Social and Technical ,the work system needs to be reviewed and effective care to be taken to ensure that there are no Silos in the work place this is important in creating a system taking care of optimizing the work', (Toni, Maria and Eileen 2003)

\section{LITERATURE REVIEW}

\section{A. Strategy in leadership}

The importance and need of use of strategy in industry 4.0 is higher than it would have been in 3.0. These use of automation AI and cloud should be for definite business vision and goals and not merely to reduce manpower or optimize.

"Internal and external environment is to be taken care by strategies which define the product outcome based on the individual leader qualities ". (Bernard ,2007) 
"Mc Neilly suggested for successful industry 4.0 we need to focus on: 1. Avoid using huge unwarranted investments to destroy competition, instead it should be customer focused. 2 .

Technology should be implemented to overcome weaknesses; 3. Understand give what your competition cannot give; 4. Preparedness to handle adversity and troubleshooting and new opportunities 5. Opposition should be removed by building the right culture 6 . Treat people respect so that they can deliver with confidence". McNeilly (1996)

"Strategic leaders are futuristic who set vision for the organization" (Arnott, 1995). "Their impact is better they address with the critical factors towards the environment (Hambrick, 1981). Leaders communicate the vision in simple words" (Zaccaro)." They create goals and objectives for their organization and develop, processes, around that, building new competencies and manage various level of executives and develop them for next generation, provide guidance build a culture of respect by all in the organization, should be one strategy towards culture, maintain a system of very high ethical values, were respect to all is seen and sustained"(Bernard ,2007)

"Strategic leadership are responsible for profitability, strategies need to follow a cost reduction activities and improvements and a visual and motivated work place were visuals and information is key these builds Team work.'(Bernard ,2007)

Next generation Leader must be visionary and there should be clear vision coupled with a right strategy to suit their business goals

\section{B. Leadership transformation}

"Challenges are across boundary, so will be leadership style. There is ever changing expectations and challenges which calls for critical transformation in leadership by creating a vision, building capabilities, communicate with clarity show the direction needed, align stake holders and guide and help the team to achieve their goals". (Jeffrey, Ernst, and Michael (2011))

"The most important driver for the change is build a innovation culture for their organization. Trends show $92 \%$ of executives explained the drive for innovation as the most important part of the organizational strategy for next 5-10 years. This requires leaders to become more effective and flexible and should be able to tap diverse expertise and cultural insights to achieve the goals." (Jeffrey, Ernst, and Michael (2011))

The role of the leadership for transformation in the new era is: -

Leadership Talent: Continuous focus should be in talent development. Organization's should focus on continuously attract, build capability, so that it helps in retaining people. Strategy should be formed and executed to build right culture, Long term focus should be by systems, and processes which will help to retain.

Leadership Culture: Company should understand the need and the culture that needs to be nourished this is part leadership culture; the leader should understand the undercurrents between people and departments and should be channelized for a common beliefs and practices this should be followed by direction, alignment, and commitment.

Leadership Strategy: Strategy coupled with an effective leadership is very important or else best strategy too can fail." (Jeffrey, Ernst, and Michael (2011))

Leader should have the potential talent and drive the strategy by using culture development. change by force is ruled out. Cultural change is difficult as the voice of associate is limited in industry 4.0 (everything will be preprogramed), this will be very much needed as we may face boredom or silo effect due to lean team and less use of creativity.

\section{Leadership qualities to promote conflict and problem-solving attitude}

A sense of disconnect and questioning attitude by some team members are recommended, leadership should promote this attitude and should be able to control in very few numbers, it's should not be opposite that all the members are having conflict on idea.

Once we have a diverse view we also need to question and have a problem-solving approach. Problem solving approach is also required to solve routine and troubleshooting issues innovation brings strategic advantage. Decision making is also important.

Conflict for effective team work: Capability is improved to ensure team work depends on the conditions developed by all members to work together productivity. During the problem solving approach, open discussion of conflicting ideas will be useful." Chen, Liu and dean (2005),

Conflict in its strategic management: Chen, Liu and dean (2005), have made research on the use of conflict in its strategic management which helps to drive productive conflict thereby improving the team effectiveness this brings innovation in the business.

\section{Leadership style}

Participation or situational leadership style is the most effective leadership towards innovative approach in the industry 4.0 environment.

"leadership style is an important element of innovation. The role of leaders in the organizations is to guide and define work content that contribute to organizational innovation" (Sarros, Cooper, Santora, 2008). "Participative leadership is the best form to support the cultures of innovation and promote high-performing companies." (Ogbonna \& Harris, 2000).

"Transformational leaders build internal capability by helping followers grow and develop into future leaders, the leaders should align the objectives by empowering them." (Bass and Riggio, 2006). "This leadership consists of four elements: charismatic role, individualized, consideration, inspirational, motivation, and intellectual stimulation', (Gumusluoğlu and Ilsev 2009).

"There are six factors in the transformational Leadership Scale given by Podsakoff et al.

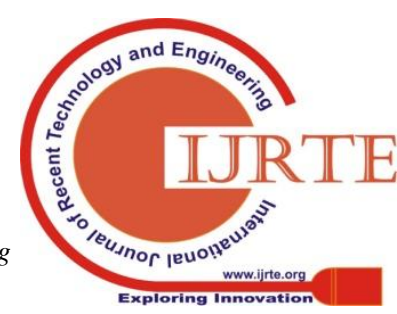


(1990) Thefactors are (a) articulates vision, (b) provides appropriate role model, (c) building common of goals, (d) build high performance teams, (e) provides individual support, and (f) provides intellectual stimulation. These conditions stimulate the organizational Change." Katarzyna \&Woszczyna ,(2015),"Participative leadership encourages fast decision-making and can influence the leader's decisions this with autonomy helps to perform the task easily." Katarzyna \&Woszczyna ,(2015),“Constant guidance and coaching are enables for participative leadership to flourish, this helps in joint decision making and delegation" (Yukl, 2002)." These type of leadership are considered to be better than individual innovation"Katarzyna \&Woszczyna,(2015),

Participative leadership is recommended as this will be best support to culture building, other researchers are also calling by situational leadership or flexible leadership.

"To attain the job satisfaction and team work with clear clarity of roles depends on the leadership quality and focus towards social aspects, quality of relationship also depends on the leaders and followers, this is explained in the LMX theory" (Yukl, 2002). The quality of exchanges in a team also depends on the risk-taking ability and the culture of involvement and creativity." Katarzyna \&Woszczyna ,(2015),

"The behaviours of the employees are influence by leaders have a powerful source to influence employees' work behaviours" (Yukl, 2002). "The most effective leaders help individuals to coordinate and integrate as teams and build attitudes towards problem solving and creativity" (De Jong, and Den Hartog 2007). "Support and encouragement for employee at all times like mentors to achieve the organisational goals, $43.3 \%$ of the have voted that the new ideas of employees are encouraged by the organization." Katarzyna \&Woszczyna ,(2015)

The other two factors supporting the leadership for innovation's are Team reflection and Team outcomes.

Team reflection: Collective wisdom helps in team reflection and supports in achieving the team's objectives, strategies and processes" (West, 1996: 559). "Team reflection also reflect behaviours such as questioning, debating, planning, exploratory learning, analysing, divertive exploration, making use of knowledge." (West, 1996)

Team outcomes: "The desired results are achieved when the team outcomes happens and the members understand their role well',(Chatman \& Flynn, 2001). "Use of team of ideas, processes, products, or procedures helps team to understand the team outcomes well. (West, 1990). "Out of box thinking happens when engagement is good and the challenges faced by team outcomes happens" Anit Somech (2006),

\section{E. Leadership behaviour}

"Last five decades, extensive research on leadership behaviour has been done, leadership behaviour is categorised infour categories and 15 sub headings behaviours, literature that influence the effectiveness of these behaviours." Gary (2012)

As per research by Gary (2012), The leadership behaviour is classified in the following 4 heads
Task oriented: Clarifying, Planning, monitoring operations and problem solving

Result oriented: Supporting, developing, recognizing and empowering

Change oriented: Advocating change, envisioning change, encouraging innovation and facilitate collective learning

External: Networking, External monitoring and representing problem solving, supporting, empowering and networking are the behaviours which will help and promote innovation culture.

"The ever-changing and, uncertain environment, organizations need flexible leaders who are adaptive in nature. These leaders must be able to appreciate and help the team to overcome the complex relationships among performance determinants. Senior leadership must be prepared to change their leadership behaviour, the competitive strategy, and the formal programs and structures to meet the challenges that confront them in an increasingly uncertain and turbulent environment" Gary, (2008),

\section{F. Emotional leader ship traits}

Melita, Ceaser, Geralad, Anthony and Ronald,(2003) share the need and importance of ,Emotional intelligence , They have classified the following contributors to build emotional leadership

- Team leader and role identification

- Leader personality

- Team cohesion

- Trust

- Creativity

- Decision making ability

- Social loafing

- Performance

"Team members should recognize the team norms and based on the interest level and the intensity." Melita, Ceaser, Geralad, Anthony and Ronald, (2003)

"The role of the leader is to motivate, guide and support the team relationship, leader also directs and gives transformational leadership to the team, this by adhering to team standards, empowering teams and encouraging team identity and pride, Sometimes the leader should can create an atmosphere of urgency to improve oneself and team process for collective good" Melita, Ceaser, Geralad, Anthony and Ronald,(2003)

"Trust and innovative culture are built by team cohesion. This helps in efficient decision making and over all improved performance." Melita, Ceaser, Geralad, Anthony and Ronald,(2003)

\section{G. Innovative leadership}

"To solve complex problems and situations the team should understand the variables and forces, they should also harness the skills required to have a innovative culture. It requires innovation leadership". David \& Bucher, (2014),

Two components of Innovation Leadership are: -

Approach of leadership to drive innovation: The leader should cultivate team who are

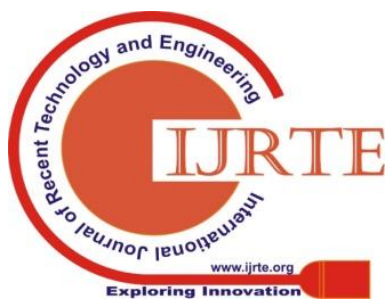


agile, they think differently and encourage team members. The leaders should be quick in the absence of information or predictability.

Leadership for innovation: "Team should have aptitude to learn the leaders must be a good learner and should create the right climate to foster innovation, support and guide to solve problems and develop new products and services.

The team should be able to think and act differently under constraint of resources and stay ahead in competition." David \& Bucher, (2014),

David \& Bucher, (2014), Suggested the following Six Innovative Thinking Skills

- Paying attention

- Personalizing

- Imaging

- Serious play

- Collaborative inquiry

- Crafting

\section{H. Innovative role modeling \& Intellectual stimulation}

"Generation of ideas happens when you Stimulate your employees with giving impossible targets or beating a bench mark company, just tempting will bring innovation culture and collectively as a team can make it happen."

'"When there are unexpected problems it's good to stay connected with the issues and open to all suggestions, leadership should have patience, these ideas when brainstormed will give the right solution, a part of participative management." Jeron and Deanne (2007),

\section{Build knowledge management (KM)}

"Knowledge management is getting importance worldwide, this will help to improve the efficiency and business processes, this needs deep dive study and each factory or company may have different needs, skill gap and effective capability building program should be planned and executed.' (Nguyen \&Mohamed, 2011). "Innovation is an outcome of the outcome of effective usage of innovation" (Darroch\& McNaughton, 2002; Du Plessis, 2007)

Identifying the need of skill and knowledge required and to give right training to suit the individual and business needs is a challenge. Other researcher has considered this a crucial factor and companies are still not clear on the training required.

\section{J. Customer focused} towards customer focus. "Innovation will impact most businesses, including logistics companies, help in product, technological and organizational innovation. The industry 4.0 implementation should always have focus on the customer needs, product innovation and improvement in logistics and services, there is huge data available, analysis thru big data and making it a business sense I required to make an excellence supply chain "Witkowski (2016),

The change in the industry 4.0 should be customer focussed, this is a very expensive and few wrong doings will be difficult to correct, conventional manufacturing it was easy and flexible. The change should be customer focussed
Leader must ensure all the innovative approach are

and should be flexible.

Greogery \& Joseph (2017), gave five priorities for 21st Century, these are applicable to the next era ie Industry 4.0

"To be competitive and be ever ready for the changing environment the leaders should focus on the following objectives:

- Strategic vision to motivate and inspire

- Empowering employees

- Sharing internal knowledge

- Integrating external information

- Challenging the status quo and enabling creativity." Greoery \&Joseph (2017),

"A culture feedback sharing approach should be encouraged wherein leaders should share feedback and take feedbacks" Jeron and Deanne (2007),

\section{CONCLUSION}

The author had collected literatures on Industry 4.0, leadership styles and behaviour, The relevant shortlisted Journals, over 75 Nos were put into Word cloud by using R studio.

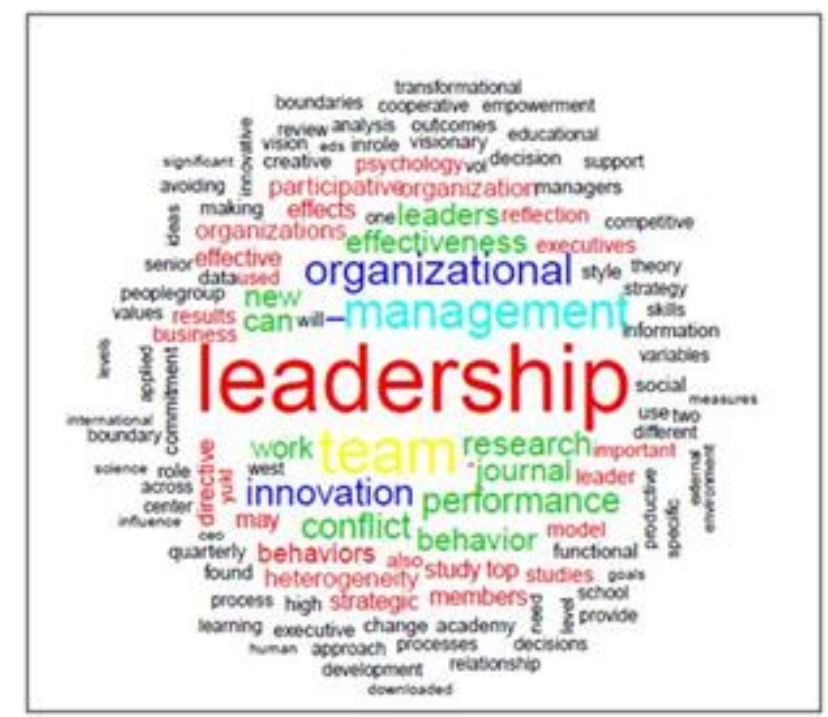

Fig 1: Word cloud was made by using all the text contents referred for literature review

The Literature review shows the need of right style of leadership. This era ie Industry 4.0 would be very different from the previous eras. All the previous era also had some uncertainty and always had resistance to change, however this one would have less of uncertainty but more of boredom and Silo effect. This change also requires innovation, but how to churn with lean and diverse team, what motivation factors will hold them, this calls for extensive research, before we step into Industry 4.0 (we are already in).

Knowledge management and situational /Participation/ flexible style of leadership is required to complete the change management.KM - Knowledge management is very crucial and needs to be understood the skill gap and the same should be bridged.

Published By:

Blue Eyes Intelligence Engineering 
With the ease in communication, the challenges are many, the curiosity is also high. More research is needed and as we experience the same we can / researchers can do more study and do statistical analysis to prove or disprove our theories.

\section{REFERENCES}

1. Aga, Noorderheaven\&Vllejo(2016), Transformational leadership and project success: The mediating role of team-building, Elesiver

2. Anit (2005), Directive Versus Participative Leadership: Two Complementary Approaches to Managing School Effectiveness, Educational Administration Quarterly, Vol. 41, No. 5 (December 2005) $777-800$

3. AnitSomech (2006), The Effects of Leadership Style and Team Process on Performance and Innovation in Functionally Heterogeneous Teams, Journal of Management, DOI: 10.1177/0149206305277799

4. Bernard M Bass (2007), Executive and Strategic Leadership, International Journal of business

5. Chen, Liu and dean (2005), Conflict management for effective top management teams and innovation in China, Journal of management studies

6. Colette (2014), Visionary leadership and its relationship to organizational effectiveness, Leadership \& Organization Development Journal, Research Gate,DOI: 10.1108/LODJ-10-2012-0130

7. David \&Bucher ,(2014),innovative leadership- how to use innovation to lead effectively, work collaboratively and drive results , Centre for creative leadership

8. Gary, (2008), How leaders influence organizational effectiveness, lsevier,Doi:10.1016/j.leaqua.2008.09.008

9. Gary (2012), Effective Leadership Behavior: What We Know and What Questions Need More Attention, Academy of Management Perspectives, DOI: $10.5465 / \mathrm{amp} .2012 .0088$

10. Greogery\&Joseph,(2017), Changing Roles:Leadership in the $21 \mathrm{st}$ Century. Organizational dynamics

11. Jeffrey, Ernst, and Michael (2011), Centre for Creative Leadership,book titled Boundary Spanning Leadership: Six Practices for Solving Problems, Driving Innovation, and Transforming Organizations by Chris Ernst and Donna-Chrobot Mason

12. Jeron and Deanne (2007), How leaders influence employees'innovative behaviour, European Journal of Innovation,pp. 41-64, Emerald Group Publishing Limited ,DOI 10.1108/14601060710720546

13. Katarzyna \&Woszczyna ,(2015), Leadership and organizational culture as the normative influence of top management on employee's behaviour in the innovation process, Elsevier

14. Mario and Jesus,(2013), The role of knowledge-oriented leadership in knowledge management practices and innovation, Elsevier

15. Melita,Ceaser,Geralad, Anthony and Ronald,(2003),Emotional intelligence, leadership and effectiveness, and team outcomes, The international journal of organisational analysis

16. Saqib,Shang,Hognian\& Yun , (2016) Management approaches for Industry 4.0: A human resource management Perspective ,Research gate ,DOI: 10.1109/CEC.2016.7748365

17. Witkowski (2016), Internet of Things, Big Data, Industry 4.0 - Innovative Solutions in Logistics and Supply Chains Management, Elsevier

18. Abshiek ,Rajbir,Harwinder (2014) Total Productive Maintenance, Research gate

19. Kathleen, Roger \&Kristy (1999) The impact of Total Productive maintenance on measuring performance, Elsevier

20. Van MielroH(2003)Self managing team work and psychological well being, Technische Universiteit Eindhoven

21. JannesSlomp and Eric ( 2002 ) "Cross - training and team performance", Taylor and Franics

22. Steve (2001) "work Groups and Teams in organisation", Cornell university ,ILR School

23. Marks, Sabella,Burke, and Zaccro ( 2002), " The impact of cross training on team effectiveness.

24. Kenneth \& David ( 1990) "Work team and effectiveness ", Research gate

25. Shelly (2004) Transformational leadership and team performance, Research gate

\section{AUTHOR PROFILE}

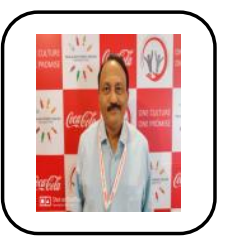

Mr. S. Sridhar, Faculty in School of Management, SRM Institute of Science and Technology, Chennai As a part of business excellence, I am a TPM (Total Productive Maintenance), instructor and practitioner, have transformed over 10 plants to world-class levels( won JIPM TPM excellence awards ) In pursuit of excellence, working on Self -Managed lines and am successful in 4 lines in Coca-Cola My Research is " Sustenance of Self -managed lines over a period of time ". 